конечно, условность этого обозначения) и объединим под этим наименованием случаи, в которых машины являются коммуникантами и текстопроизводителями.

Представляется, что эта исследовательская схема может оказаться весьма перспективной при определении тех направлений, в которых язык осваивает новые, человекоподобные, амплуа машины.

1. Словарь русского языка : в 4 т. / РАН, Ин-т лингвистич. исследований ; под ред. А. П. Евгеньевой. 4-е изд., стер. М. : Рус. яз. ; Полиграфресурсы, 1999. Т. 2. 736 с. URL: http://feb-web.ru/feb/mas/mas-abc/13/ma223926.htm?cmd= 0\&istext=1 (дата обращения: 12.06.2019).

2. Ожегов С. И. Толковый словарь русского языка. М. : Оникс ; Мир и образование, 2009. 736 с.

3. Одинцова М. П. Основные понятия лингвоантропологии // Лингвистика человека: антология / под ред. Л. Б. Никитиной, Н. Д. Федяевой. Омск : Вариант-Омск, 2012. 360 с.

4. Афроризмы и цитаты про труд // Citaty.su. URL: http:// citaty.su/aforizmy-i-citaty-pro-trud-rabotu (дата обращения: 12.06.2019).

5. Цитаты о труде // Time365.info. URL: https://time365. info/aforizmi/temi/trud (дата обращения: 12.06.2019).

6. Афоризмы и цитаты про лень // Citaty.su. URL: http://citaty. su/aforizmy-i-citaty-pro-len (дата обращения: 12.06.2019).

УДК 81 '33

Науч. спец. 10.02 .01

DOI: 10.36809/2309-9380-2019-24-111-114

\section{МАРКЕРЫ ВОЗРАСТНОЙ СТРАТИФИКАЦИИ В ДИАЛЕКТНОМ ДИСКУРСЕ И ТЕМАТИЧЕСКАЯ РАЗМЕТКА ТЕКСТА*}

В статье анализируются возрастные маркеры, встречающиеся в диалектных высказываниях и репрезентирующие возрастную самоидентификацию диалектоносителей старшего поколения. По результатам исследования выявлены наиболее частотные маркеры возраста в диалектном дискурсе. Анализ «речемысли» диалектоносителей доказывает значимость концепта ВОЗРАСТ для их самоидентификации и способствует выработке методики тематической разметки диалектных текстов для размещения в региональном корпусе народной речи Среднего Прииртышья.

Ключевые слова: возрастная стратификация, возрастная самоидентификация, языковые маркеры, тематическая разметка диалектного текста.
7. Цитаты о лени // Time365.info. URL: https://time365. info/aforizmi/temi/len (дата обращения: 12.06.2019).

8. Пословицы и поговорки про инструмент // Сборник народной мудрости. URL: https://sbornik-mudrosti.ru/poslovicyi-pogovorki-pro-instrument (дата обращения: 12.06.2019).

9. Никитина Л. Б. Категориальные семантические черты образа homo sapiens в русской языковой картине мира : моногр. Омск : Изд-во ОмГПУ, 2004. 148 с.

10. Богачева Р. А. Проблема недоопределенности значения термина «искусственный интеллект» // Гуманитарная информатика. 2011. Вып. 6. URL: https://cyberleninka. ru/article/n/problema-nedoopredelennosti-znacheniya-terminaiskusstvennyy-intellekt) (дата обращения: 12.06.2019).

11. Федяева Н. Д. Машина умная, человек продуктивный: о современных акцентах взаимодействия образов машины и человека в русской языковой картине мира // Новейшая филология: итоги и перспективы исследований : сб. ст. I отв. ред. О. В. Золтнер. Омск : Изд-во Ом. гос. ун-та, 2019. C. $126-130$.

12. Demchenkov Sergei A., Fedyaev Dmitry M., Fedyaeva Natalia D. "Autopoet" Project: a Semantic Anomalies Generator or a New Existence Creator? // Astra Salvensis - review of history and culture. Year VI, Supplement no. 1, 2018. P. 639646.

() Федяева Н. Д., Демченков С. А., 2019

\title{
AGE STRATIFICATION MARKERS IN DIALECTAL DISCOURSE AND THEMATIC TEXT MARKING-OUT*
}

The article analyses the age markers found in dialectal statements that represent the age self-identification of the aged dialect speakers. The results of the study revealed the most frequent age markers in the dialectal discourse. The analysis of "speech ideas" of dialect speakers proves the importance of the AGE concept for their self-identification and contributes to the developing the method of thematic marking out of dialect texts to be placed in the regional corpus of the Middle Irtysh region folk speech.

Keywords: age stratification, age self-identification, language markers, thematic marking-out of dialectal text.

Известно, что современная лингвистика, и зарубежная, и отечественная, с 80-90-х гг. XX в. обратилась к дискурсивному анализу, который «существует в условиях плюрализма» - последнее, безусловно, связано с многообразием «как методов анализа, так и определения самого объекта анализа - дискурса» [1, с. 139]. По справедливому замечанию В. Е. Чернявской, «<...> адекватность выбора дискурсивного метода работы с языковыми фактами существенно

\footnotetext{
“ Статья подготовлена при финансовой поддержке РФФИ; проект № 18-012-00519.

The article has been prepared with the financial support provided by RFBR; project No 18-012-00519.
} 
влияет на интерпретацию результата анализа» [1, с. 139], а «выход исследовательского интереса лингвиста за границы предложения и далее за границы текста обусловил становление лингвистики дискурса как самостоятельной дисциплины» [1, с. 140]. Становление такой дисциплины исследователи связывают с ориентацией ее не на языковые структуры или отдельные тексты, а на корпус текстов [2, c. 7-8].

В рамках гранта Российского фонда фундаментальных исследований (РФФИ) ведется работа над созданием регионального корпуса народной речи. Полагаем, что именно народная речь не только позволяет объемнее воссоздать национальную картину мира, но и дает возможность проводить исследования русской речи полиэтнического региона в разных аспектах: дискурсивном, гендерном, лексико-семантическом, структурно-грамматическом, динамическом, историко-этимологическом, лексикографическом и др., см. подробнее о структуре корпуса и его специфике [3]. Об актуальности и значимости создания корпусов текстов на диалектном материале пишут многие исследователи $[4 ; 5 ; 6]$.

В контексте предпринятого исследования необходимо указать, что создаваемый аннотируемый корпус ориентирован на тематическую разметку как на основную [7]. Одна из задач, стоящих перед лингвистами - участниками проекта, - это выявление актуальных для сельских жителей тем, репрезентированных в текстах. Тексты представляют собой расшифрованные аудио- и видеозаписи бесед с диалектоносителями во время ежегодных диалектологических экспедиций, начиная с 70-х гг. XX в. и по настоящее время. Тексты в корпусе приводятся в полном объеме, при этом мы намеренно исключаем искусственное деление на фрагменты по темам. Поскольку корпус носит динамический характер (т. е. возможно пополнять корпус новыми материалами по мере их получения и обработки), то и список тем по мере пополнения корпуса будет расширяться.

Объектом настоящего исследования стали диалектные высказывания, репрезентирующие возраст пожилых людей, поскольку именно они, люди старшего поколения, как правило, являются нашими основными информантами, а тема «возраст» оказывается частой в беседах с ними.

Целью настоящего исследования стало выявление маркеров возраста диалектоносителей старшего поколения для дальнейшей тематической разметки текстов в корпусе народной речи Среднего Прииртышья.

С точки зрения психологии возрастные различия между людьми можно считать основой их самоидентификации. На протяжении различных исторических эпох с изменением социальной жизни, верований, традиций менялись и критерии возрастной стратификации. Как и в ранние эпохи, наряду с выделенным хронологическим, календарным возрастом и представлениями о нем, существует возраст условный. Представления о нем варьируются в различных социокультурах [8; 9].

Известный советский и российский ученый И. С. Кон создал систему «возрастного символизма», в которую включил нормативные критерии возраста, а также стереотипы и представления, связанные со взрослением. Кроме того, И. С. Кон выделил особую категорию субъективного, пере- живаемого, возраста. Под ней подразумевалось «возрастное самосознание, зависящее от напряженности, событийной наполненности жизни и субъективно воспринимаемой степени самореализации личности» [10, с. 54].

На основании анализа записей диалектоносителей преклонного возраста (60 лет и старше), собранных на территории Среднего Прииртышья, отобраны тексты с лексическими, морфологическими и иными приметами, актуализирующими названный возраст.

Экстралингвистические факторы играют значительную роль в самоидентификации диалектоносителя преклонного (это прилагательное используем синонимично со словом пожилой) возраста.

В речи диалектоносителей находим большое количество высказываний, где сквозь призму оппозиции «раньще сейчас» информанты оценивают свой теперешний возраст, свою современную жизнь. Оппозиция может выражаться на уровне контекста, например, обращением к нынешней, «хорошей» жизни и сравнением ее с прошедшей тяжелой порой, и одновременно дается оценка себя и своего возраста лексически с помощью прилагательного с корнем cmap-:

У-мене эта ниче / память // Жысь харошая / но мы уже старые // Жысь харошая дуракам дасталась // (с. Седельниково, Седельниковский р-н, А. А. Зеленова, жен., 89 лет, 4 кл., новосел., 2011).

С прошлой жизнью ассоциируются жизненные тяготы и тяжелый труд:

Дешач'ки ни-дай бох штоп вам так ни-пришлось какмы пражыли // (с. Седельниково, Седельниковский р-н, А. А. Зеленова, жен., 89 лет, 4 кл., новосел., 2011). Возраст здесь не эксплицирован, а передан через глагол пражыли, содержащий сему длительности, протяженности жизненного пути.

Респонденты отмечают, какой большой жизненный путь они прошли для того, чтобы достичь наконец стабильной, спокойной жизни, зачастую пытаются обратить на это внимание молодежи, что вызывает пересечение с оппозицией «молодость - старость», выражаемой контекстуально и при помощи непосредственных обращений к молодежи:

He / эта у-нас ни-черта ни-было / а так wom // Hy-хто / маладые / так и-щас шон w-дом кул'туры фрсе / а мы-та шо? // Мы эта самая тижолая жысь пражыли // Wойната // Харашо пражыли / памирать можна // (с. Седельниково, Седельниковский р-н, А. А. Зеленова, жен., 89 лет, 4 кл., новосел., 2011). Здесь молодость есть, а старость репрезентируется косвенно - отнесенностью к прошлому: тяжелая жизнь, прожили, помирать можно.

Аналогично и в следующих фрагментах речи диалектоносителей:

Дешач'ки ни-дай бох штоп вам так ни-пришлось какмы пражыли // (с. Седельниково, Седельниковский р-н, А. А. Зеленова, жен., 89 лет, 4 кл., новосел., 2011);

И-жыли фрсю-жыснь пятеро детей нарадили // (с. Сeдельниково, Седельниковский р-н, А. В. Храпова (Петухова), жен., 78 лет, ?, старож., 2011). Возрастные параметры в подобных контекстах могут содержать и указание на объективный возраст информанта, часто с семантикой приблизительности (за-семисят пять лет): 
У-меня стаж бал'шой / аднака пит'десят шэсть лет стажа у-меня стаж бал'шой / я старажыла w-раиспалкоме за-семисят пять лет // (с. Седельниково, Седельниковский р-н, А. А. Зеленова, жен., 89 лет, 4 кл., новосел., 2011).

Оппозиция «молодость - старость» в речи респондентов объективируется как при рассказе о нынешней молодежи, так и в воспоминаниях самих диалектоносителей о временах их молодости:

Вот так-вот тут вышла замуш за-этаво за-деда // Ну не-дед был маладым был мне было двацать три года // (с. Седельниково, Седельниковский р-н, А. В. Храпова (Петухова), жен., 78 лет, ?, старож., 2011). Собеседник свой возраст передает и лексически, указывая на «современный статус» своего мужа и называя его дедом.

Относительный возраст может быть выражен через лексемы внук, парень, также косвенно указывающими на современную социальную роль информанта:

Внукам ну-чё по-двацать ани ужэ у-нас парни // (с. Седельниково, Седельниковский р-н, А. В. Храпова (Петухова), жен., 78 лет, ?, старож., 2011).

Показателен и диалог респондента с интервьюерами, где не эксплицируется возраст информанта, а проявляется оценка возраста интервьюеров (ищё мала) и их социального статуса (ищё ни-замужьм-жы):

Должны-уш знать / ни-мален'кие // Скол'ка / па-сколь вам лет-та? //

[По двадцать].

Па-двацать? / так эта ище мала //Ище ни-замужым-жы? // (с. Седельниково, Седельниковский р-н, А. А. Зеленова, жен., 89 лет, 4 кл., новосел., 2011), - с высоты прожитых лет оценивается молодое поколение.

Значимым и частотным критерием оценки своего возраста для диалектоносителей становится физиологический фактор. С годами здоровье тела и ясность рассудка теряют свои позиции: становится сложнее следить за хозяйством, подводит память, начинают заговариваться. Маркерами здесь становится оценочная лексика с корнем стар-, лексика, связанная с общим состоянием организма (не-маuуада - «непригодные для активной работы, ведения хозяйства в связи с общим состоянием организма»), с болезнями, нездоровьем (маюсь сижу):

[А церковные праздники сейчас какие-нибудь отмечаете?]

Мы теперь ужэ старые // (с. Игоревка, Муромцевский р-н, А. С. Иванова, жен., 80 лет, 3 кл., новосел., 2010);

[Как хозяйство ведете?]

Ну-вели а-щас ужэ не-маи уада ужэ вес'ти // (с. Игоревка, Муромцевский р-н, И. П. Камнев, муж., 69 лет, 6 кл., рус.-бел., 2010);

Жывем харашо / но толку-та нет / старые // Hy-wom и-я маюсь сижу // (с. Седельниково, Седельниковский р-н, А. А. Зеленова, жен., 89 лет, 4 кл., новосел., 2011);

Плоха у-мене зрение / плоха / я думала никада я такая слипая ни-буду как у-меня глаза были яркой // Wom сабиремся ран'шы / чилавек пять // (с. Седельниково, Седельниковский р-н, А. А. Зеленова, жен., 89 лет, 4 кл., новосел., 2011);

Уu-wce пазабыла / терь-шон сеня пгврю / заштра ниче ни-знаю / рас-уш старасть так дураки али палудурки или-што // Нu-nайму-што старасть // Щяс-уш щитай я и-тиливизар ни-сматрю // Я плоха и-вижу / плоха я вижу // Eтот сафсем плоха глас смотрит и-етот // Woт манен'ко и своих жэнщин ни-узнаю / блиска-та узнаю а далека // (с. Седельниково, Седельниковский р-н, А. А. Зеленова, жен., 89 лет, 4 кл., новосел., 2011).

Детерминантом пожилого возраста выступает лексема смерть как итог жизни, сопутствующая рассуждениям об утрате сил, одиночестве в старости:

Он ужэ старый был ужэ Феликсавна умирла он адин астался 3-доч'кай с-той // (г. Тара, Тарский р-н, А. П. Петрович, жен., 84 года, ср.-спец.,рус.-польск., 2010);

А-я ну-фр-то время што я саабражала? / сичяс вот-и мален'кий бол'шы саабражаит / ну-как эта смерть што эта за-смерть я как ана заглядыват? / типерь я знаю как ана заглядывает в-глаза // (г. Тара, Тарский р-н, А. П. Петрович, жен., 84 года, ср.-спец., рус.-польск., 2010).

Пора преклонного возраста представляется как пора увядания, накопленного большого жизненного опыта и определенного социального и семейного статуса. Для номинации используются лексемы дед, баба и аналогичные обращения, а также обозначения с корнем стар-:

Двое з-дедом жывем; // И-ездят з-дедом маим // (с. Ceдельниково, Седельниковский р-н, А.В.Храпова (Петухова), жен., 78 лет, ?, старож., 2011);

Bот меня спрашывают у-тебя баба Аня легкая рука? (с. Седельниково, Седельниковский р-н, А.В.Храпова (Петухова), жен., 78 лет, ?, старож., 2011);

Вот прийдись так найдеш старух или нет штоп-вот нипол'завациа ап'теками этими ф'сякими // (д. Чекрушева, Тарский р-н, 3. Г. Иванова, жен., 81 год, ср.-спец., старож., 2010);

А-у-наз был стораш старик // (г. Тара, Тарский р-н, А. П. Петрович, жен., 84 года, ср.-спец., рус.-польск., 2010).

Стоит отметить, что в зависимости от коммуникативной ситуации слово старики может выступать как номинацияобобщение для всех людей преклонного возраста:

Дажы старики прихадили // (д. Чекрушево, Тарский р-н, А. И. Иванов, муж., 74 года, 2 кл., старож., 2010).

Для обозначения возрастной группы людей пожилого возраста используются обобщенные номинации старые люди, пожилье:

Ран'шэ старые люди / вот как моя бабушка / они пяшком ходили /это ран'шэ // (с. Алексеевка, Муромцевский р-н, Н. И. Вальновская, 81 год, 7 кл.,рус.-бел., 2010);

Каждый берет вот / пажылые жэнщины работат // (с. Седельниково, Седельниковскй р-н, Л. Д. Фешина, жен., 81 год, неграмот., старож., 2011).

Прожитые годы дают основания для представления (и противопоставления) себя не только как личности из другой эпохи, но и абсолютно другого уровня ума и знания жизни, хотя в контексте не эксплицируется старость, сегодняшнее время и состояние информанта, но ясно, что старость (сегодня, сейчас) диалектоноситель сравнивает (сравнение с несуществующим, не выраженным в дискурсе грамматически и/или лексически предметом речи) с порой молодости, когда не было опыта, бытовых навыков и тех знаний, что приобретаются с опытом жизни:

А аткуда я че-знала? // Ниче ни-знала // Восимнацать лет // Дивитнацатьй мне ужэ с-апреля пашол / а я фртарова июля Галю радила // (с. Седельниково, Седельниковский р-н, Л. Д. Фешина, жен., 81 год, неграмот., старож., 2011); 
ЯЗЫКОЗНАНИЕ

Я гворю ну че-мне токо восемнацать ишо в-апреле исполница // Какая я ниче ни-умею делать // Ну-гатовить там картошку пачис'тить // (с. Седельниково, Седельниковский р-н, Л. Д. Фешина, жен., 81 год, неграмот., старож., 2011).

Таким образом, анализ записи речи жителей Среднего Прииртышья подтвердил, что возраст действительно является значимым концептом для самоидентификации диалектоносителя. Для человека преклонного/пожилого возраста - это определение себя как личности другой эпохи, особого социального статуса, завоеванного многолетним опытом, но изменение современной жизни в лучшую сторону не дает полной радости из-за фризиологических проблем, слабого здоровья, одиночества. Указание на объективный хронологический возраст посредством числительных отмечается не так часто, при этом может быть указан не точный, а приблизительный возраст (уже за..., скоро уж...) и т. п. Маркерами возраста в тексте могут выступать лексические средства - номинации дед, баба, пожилой, слова с корнем стар-, содержащие сему «возраст пожилого человека». Относительный возраст предстает и через косвенное указание: возможны лексемы с близкой семантикой (пенсия, век) или слова, репрезентирующие нездоровье (маяться, мучиться); детерминантом выступает и лексема смерть как итог жизни; через основные оппозиции «старость молодость», "раньще - сейчас» и др.

Считаем, что тематическая разметка для регионального корпуса предполагает предварительный когнитивнодискурсивный анализ расшифрованных экспедиционных диалектных материалов. Поэтому использованная в статье методика анализа позволила не только точнее выявить параметры подтемы «пожилой /преклонный возраст» как фррагмент темы «возраст», но и в дальнейшем позволит уточнить список тем, актуальных для мировидения сельских жителей полиэтнического региона в целом.

1. Чернявская В.Е. Методологические возможности дискурсивного анализа в корпусной лингвистике // Вестн. Том. гос. ун-та. Филология. 2017. № 50. С. 135-148.

2. Плунгян В. А. Корпус как инструмент и как идеология: о некоторых уроках современной корпусной лингвистики // Русский язык в научном освещении. 2008. № 2. С. 7-20.
3. Харламова М. А. О региональном корпусе народной речи: к постановке проблемы // Актуальные проблемы обучения русскому языку XIII [Current issues of the Russian language teaching XIII] / ed. Simona Koryčánková. Брно, Masarykova univerzita, 2018. C. 217-223.

4. Гольдин В. Е., Крючкова О. Ю. Проблемы создания электронного диалектного корпуса // Русская устная речь. Материалы Междунар. науч. конф. «Баранниковские чтения. Устная речь: русская диалектная и разговорно-просторечная культура общения» и межвузовского совещания «Проблемы создания и использования диалектологических корпусов» (Саратов, СГУ, 15-17 ноября 2010 г.) / под ред. О. Ю. Крючковой. Саратов : Наука, 2011. С. 249-260.

5. Качинская И. Б., Сичинава Д. В. О Корпусе диалектных текстов в Национальном корпусе русского языка // Вопросы лексикографиии. 2017. № 11. С. 71-82.

6. Харламова М. А., Лавров Д. Н. История полиэтнического региона в «зеркале» народной речи: о проекте регионального диалектного корпуса // Актуальные проблемы и перспективы русистики. Материалы по итогам Междунар. конф. русистов в Барселонском университете, МКР-Барселона 2018 / ред. Ж. Кастельви, А. Зайнульдинов, И. Гарсия, М. Руис-Соррилья. Барселона : Trialba Ediciones, 2018. С. 1564-1572.

7. Лавров Д. Н., Костюшина Е. А., Харламова М. А. Представление разметки корпуса народной речи Среднего Прииртышья // Математические структуры и моделирование. 2018. № 4(48). С. 85-91.

8. Социология : учеб. / Ю. Г. Волков, В. И. Добреньков, В. Н. Нечипуренко, А. В. Попов ; под ред. Ю. Г. Волкова. 2-е изд., испр. и доп. М. : Гардарики, 2003. 513 с.

9. Лантюхова Н. Н. Некоторые проблемы возрастной периодизации развития личности в современных научных исследованиях // Современная наука: опыт, проблемы и перспективы развития : материалы Междунар. науч.-практ. конф. / гл. ред. Д. А. Ефремов ; отв. за вып. А. И. Вострецов (Нефтекамск, 30 сентября 2015). Нефртекамск : Научно-издательский центр «Наука и образование», 2015. С. 53-55.

10. Кон И. С. Ребенок и общество. М. : Наука, 2003. $270 \mathrm{c}$.

(C) Харламова М. А., Москаленко В. С., 2019 